\title{
La inspección de abastos en Madrid durante la Edad Moderna. Un problema de competencias
}

\author{
ana Guerrero Mayllo
}

El interés despertado en los últimos años por el estudio del régimen municipal de nuestros pueblos y ciudades es una realidad incuestionable.

Sin embargo, la mayoria de los trabajos se han orientado hacia el análisis de la progresiva pérdida de autonomía de los ayuntamientos por la fiscalización que ejerce la Corona a través del corregidor cuando no hacía una sociología del poder centrada en el grupo más influyente que dirige la institución, los regidores, o hacia otros campos relacionados con el gobierno municipal: hacienda, beneficencia, etc. '.

Con todo, hay cargos que, quizá pensando en su menor relevancia, se ignoran o pasan un poco desapercibidos, sin darnos cuenta de que

- Enumerar aquí todos ellos es tarea casi inabarcable. Sólo a título de ejemplo citaremos: R. GiBert: El concejo de Madrid, su organización en los siglos XI al xv, Madrid 1949. M. Gonzalez Jimenez: El concejo de Carmona a fines de la Edad Media, Sevilla 1973. J. LaSAOSA VILlanUa: El regimiento municipal de Pamplona en el siglo xvi, Pamplona 1980. A. SaCRISTÁ Martinez: Municipalidad de Castilla y León. Madrid 1981. E. LoRENTE: Gobierno y Administración de la ciudad de Toledo en la segunda mitad del siglo xVI. Toledo 1982. A. J. SAnchez Pérez: Poder municipal y oligarquía. El concejo cacereño en el siglo XVII, Cáceres 1987. P. ORTEGo GIL: Organización municipal de Sigüenza a finales del Antiguo Régimen, Guadalajara 1986. M. C. ROMEO MATEO: Realengo y Municipio. Alcoy en el siglo xVIII, Alicante 1986. J. Rodriguez Espinosa y Callejas Rodriguez: Villamayor. Un municipio del Campo de Calatrava en el siglo xvil, Ciudad Real 1983. El Gobierno Municipal de la Villa de Madrid durante el siglo xvi, asi como la sociología de sus componentes es el objeto de mi Tesis Doctoral, en curso de realización. 
por sí solos, con el único cometido de sus funciones y a través de sus relaciones con los otros oficiales, son capaces de generar un amplio abanico de tensiones que en absoluto podemos obviar si es que queremos conocer todos los entresijos de las ciudades modernas. Nuestro trabajo, por lo tanto, pretende dedicar unas páginas a dos de los oficios que Tomás y Valiente ha denominado "de dinero", nos referimos a los Fieles de vara y fieles ejecutores, encargados de labores tan delicadas como el control de precios y de abastos, los pesos y medidas, la limpieza y ornato de la villa, entre otras. Su estudio nos resulta sugerente porque a través de él contemplamos fenómenos típicos del período que nos ocupa: patrimonialización del cargo, conflictos en los procesos electorales, fraudes en su gestión y tensiones jurisdiccionales con los representantes del poder real. Ciertamente, las conclusiones que podemos extraer no tienen un carácter general pero tampoco pretendemos otra cosa que ofrecer una primera aproximación sobre el gobierno municipal de Madrid en la Edad Moderna, como anticipo de futuros trabajos de mayor contenido.

Madrid, a mediados del siglo XVI empezaba a alcanzar un importante peso político al convertirse en sede de la Corte. De idéntica manera crecían los problemas urbanos que se iban a desatar a partir de aquel mes de junio de 1561. La infraestructura de una ciudad que de unos 20.000 habitantes pasa, en menos de cuarenta años, a 100.000 por fuerza se tiene que resentir, incidiendo de una manera clara y precisa en la vida cotidiana de la villa ${ }^{2}$. Los Libros de Acuerdos del Concejo se hacen eco de muchas de las irregularidades desencadenadas que van desde la higiene ${ }^{3}$ hasta la subida indiscriminada de los precios de los

2 M. Fernandez Álvarez: El Madrid de Felipe /l (En torno a una teoría sobre la capitalidad), Real Academia de la Historia, Madrid 1987, p. 35. Sobre las cifras de población en Madrid en este periodo, existen innumerables testimonios tanto de cronistas locales como extranjeros. Algunos pueden resultar desorbitados como el que aporta Jerónimo de la Quintana, quien afirma que en 1598 , se daba una población de 300.000 personas: $A$ la muy antigua, noble y coronada villa de Madrid. Historia de su antigüedad y nobleza, Madrid 1629. Fol. 331 v. Noticias del aluvión demográfico también en A. LEON PINELO: Anales de Madrid (1447-1658), Madrid 1971; y J. Álvarez de BaENA: Compendio histórico de las grandezas de la coronada villa de Madrid, Corte de la Monarquía de España, Madrid 1785. Una referencia interesante de la opinión extranjera al respecto nos la ofrece A. ALVAR EzQUERRA: Felipe II, la Corte y Madrid en 1561, Madrid 1985; algunas de las cifras oscilan entre las 35.000 almas para 1572, y un cuarto de millón, p. 66. Son cifras, queremos insitir, algunas de ellas disparatadas pero no por ello dejan de evidenciar el importante crecimiento registrado en la villa.

${ }_{3}$ Archivo de Villa de Madrid (AVM). Libros de Acuerdos. Sesión del 12-IX-1561, en ella un regidor manifestaba su preocupación diciendo que "están muy suzias las calles desta villa por estar la Corte en ella y dos cherriones que ay pa limpiarlas no basta..." 
mantenimientos. Pocos meses antes de la llegada definitiva del Rey, los vecinos de la villa se querellaban contra la mala gestión del Ayuntamiento en la postura y coste de la carne ${ }^{4}$. Esta situación se vio agravada posteriormente. Algunas fechas después del establecimiento de la Corte, la necesidad de cebada para las caballerizas reales había originado la confiscación del producto a los labradores del contorno de Madrid ${ }^{5}$. Hacia 1600 , y en visperas del traslado de la capitalidad a Valladolid, proseguian escuchándose voces en torno al «daño questa rrepublica a rresçivido a causa de haverse suvido generalmente todos los mantenimientos y otras cosas que se venden de ordinario en ella y lo mucho que importa que se rremedie, y pongan justos y moderados presçios...." ${ }^{6}$. En esta misma línea hay que recordar las denuncias de Pérez de Herrera y su convencimiento de que si se quiere conservar la Corte en Madrid es preciso regular de manera más adecuada el grave problema del abastecimiento de sus vecinos ${ }^{7}$.

Ante esta situación procede plantearse algunas preguntas: ¿con qué medios contaba el Concejo para paliar estas dificultades?, ¿qué política siguió al respecto?

${ }^{4}$ Ibidem. Sesión del 19-IV-1560.

${ }^{5}$ Ibidem. Sesión del 3-VII-1561.

${ }^{6}$ Ibidem. Sesión del 13-X-1600. No sólo los Libros de Acuerdos reflejan estas cuestiones. Cronistas de la época como CaBRERA DE CORdoba en Felipe II, rey de España, 4 vols. Madrid 1876-1877 y posteriormente J. AMADOR DE LOS Rios: Historia de la villa y Corte de Madrid, Madrid 1860 , t. II, recogen importantes datos y nos ilustran perfectamente. Sobre ello, véase también M. Fernandez Álvarez: "El Madrid de 1586", en Madrid en el siglo XVI, Madrid 1982. P. 363. A. Alvar Ezquerra: op. cit., p. 63.

7 C. Perez de Herrera: A la Católica Real Magestad del Rey D. Felipe III, nuestro Señor cerca de la forma y traça, como parece podrian remediarse algunos pecados, excesos y desordenes, en los tratos, vastimentos y otras cosas de que esta de Madrid tiene falta..., Madrid 1600. Entre las soluciones apuntadas tenemos: sanear moralmente la Corte; proponer la forma para que los mantenimientos, la leña y el carbón y todas las necesidades para el vivir pudiesen adquirirse en cantidad y más moderados precios; dar traza fácil a fin de que las calles estuviesen limpias para preservar la salud, la purificación del aire y aguas de ella; que las personas con cargos tuviesen aposentamiento adecuado; aumentar hasta cuarenta los carros de basura y lodo; etc. Citado por A. GonZALEZ DE AMEZUA: «EI bando de policia de 1591 y el pregón general de 1613 para la villa de Madrid", Revista de la Biblioteca, Archivo y Museo, Ayuntamiento de Madrid, Año X, abril 1933, No. 38, p. 143. 


\section{FUNCIONES Y COMPETENCIAS DE LOS FIELES EJECUTORES Y FIELES DE VARA}

Tradicionalmente, y al igual que en otros lugares del Reino, la politica de precios, abastos y limpieza correspondía a los regidores pero con el fin de hacer cumplir sus decretos designaban a unos oficiales, los fieles de vara. En Madrid, merced al trabajo de Gibert, conocemos sus antecedentes a lo largo de la Edad Media ${ }^{8}$. A los primitivos «fiadores" suceden los fieles que, necesariamente, han de ser elegidos por el regimiento, desde 1455 -el procedimiento se estabiliza en 1477- por colaciones y por suertes. Sus atribuciones, muy amplias en el momento de su creación, se van progresivamente limitando a partir de 1478 y, sobre todo, de 1500 , con la publicación de unas ordenanzas y la presencia de la Justicia y los regidores en muchos de sus cometidos. Éstos no eran pocos: siguiendo a Gibert, vemos cómo están encargados de ordenar el mercado sellando, ajustando y concertando los pesos, medidas y varas, especialmente del pan y la carne; moderar las ganancias de los regatones, interviniendo muy directamente en las reventas; visitar, con idéntico fin, los lugares de la tierra, pudiendo permanecer en su término hasta un máximo de seis días; atender a la higiene y limpieza de vías públicas y establecimientos; y observar la correcta aplicación de la tasa de precios elaborada por el Ayuntamiento. Al parecer, no gozaban de las preeminencias de ninguno de los oficiales y tampoco obtenían un salario fijo del Concejo ${ }^{9}$.

A mediados del siglo XVI el sistema descrito resultaba insuficiente para solucionar el abasto de Madrid así como las infracciones que cometían los mercaderes, dado el incremento de la demanda de géneros provocada por el rápido crecimiento de la villa. Como lo expone el procurador general del ayuntamiento en 1564: los dos fieles de vara, pese a coordinar sus tareas con los dos regidores que se eligen cada mes para "residir" en la plaza, no pueden visitar los lugares y tiendas donde

${ }^{8}$ R. Gibert: Op. Cit. p. 244. Antecedentes del personaje los encontramos en los trabajos de J. A. Bonachia: El concejo de Burgos en la Baja Edad Media (1345-1426), Burgos 1978. I. FALCON PÉREz; Organización municipal de Zaragoza en el siglo XV. Zaragoza 1978. M. F. LAREDO QUESADA: Gobierno, hacienda y actividad económica de una ciudad en el sector occidental de la cuenca del Duero. Zamora en época de los Reyes Católicos. Tesis Doctoral inédita. Valladolid 1987. J. PÉREZ DE AYALA: "Los fieles ejecutores de Canarias"; A.H.D.E., XVII-XVIII (1957-58), págs. 137-195.

${ }^{9}$ R. GIBERT: Op. cit. p. 247. 
se venden los bastimentos con la frecuencia y atención deseada, no pudiendo en consecuencia remediar, no ya los insultos que les profieren, sino tampoco los robos y engaños en que los regatones y tenderos incurren al vender las mercancías a mayor precio de la postura, haciendo "pesos faltos, de que toda la republica se queja mucho" ${ }^{10}$.

Felipe II, con la excusa de las múltiples ocupaciones de los corregidores de las ciudades más populosas del Reino, las cuales les impiden atender estos asuntos, y la incapacidad de los fieles de vara para vigilar y sancionar "la bondad, provisión y precio" de los mantenimientos, crea en 1569 los oficios de fieles ejecutores - dos en cada ciudad-que inmediatamente fueron puestos en venta a precios muy elevados. En Madrid, se vendieron a $750.000 \mathrm{mrs}$. cada uno -en 1571 el cargo de regidor se vendió a tan sólo 280.000 mrs ${ }^{11}$ - y en otras ciudades alcanzaron valores superiores. Así, Burgos pagó $1.237 .500 \mathrm{mrs}$; Murcia 975.000; Jaén, 862.500 y Málaga, 712.500 mrs. Las cifras más bajas se registraron en Tenerife, donde se pagaron $375.000 \mathrm{mrs}$; Marbella, 262.500, y Gibraltar, con un desembolso de $187.000 \mathrm{mrs}^{12}$. Un importante negocio para la Corona que seguramente vio la oportunidad de cobrar tan altos precios debido a que "el beneficio derivable de estos oficios -en palabras de Tomás y Valiente- consiste en la percepción de tasas por acto realizado o de porcentajes de las rentas cuyo depósito, 0 contabilidad o tesaurización se realiza» ${ }^{13}$. De tal manera, las cantidades recaudadas por la Corona, incluidos los lugares de Ordenes Militares fueron:

10 A.V.M. Libros de Acuerdos. Sesión del 10-X-1564.

1 Archivo General de Simancas (A.G.S.). Cámara de Castilla. "Oficios". Leg. 19.

$12 \mathrm{M}$. Cuartas Rivero: "La venta de oficios públicos en el siglo xVl» Hispania, n. ${ }^{\circ}$ 158, 1984, p. 250.

${ }_{13}$ F. TOMAS Y VALIENTE: Gobierno e instituciones en la España del Antiguo Régimen, Madrid 1982. P. 161. 


\begin{tabular}{cccc}
\hline AÑO & REINO & OADENES & CANTIDAD (mrs.) \\
\hline 1569 & 16 & & \\
1570 & 57 & 22 & 7.500 .000 \\
1571 & 29 & 12 & 36.876 .750 \\
1572 & 11 & 11 & 19.563 .750 \\
1573 & 21 & & 10.558 .000 \\
1574 & 10 & 9 & 7.048 .125 \\
1575 & 4 & & 861.694 \\
1576 & 4 & 624.900
\end{tabular}

Fuente: M. Cuartas Rivero: La venta de oficios públicos en el siglo $\mathrm{XVI}^{14}$.

El 2 de diciembre de 1569 presentan sus títulos de fielazgo en el Ayuntamiento madrileño, Marcos de Almonacid y Nicolás Suárez. El cargo, que indudablemente limitaba las prerrogativas de los regidores y fieles de vara en el gobierno de la villa, tenía las funciones siguientes ${ }^{15}$ :

- Supervisar los mantenimientos que se traían para vender en la villa a fin de evitar su mala calidad;

- Vigilar los precios de los productos de manera que fuesen justos y moderados, y establecer las posturas de las frutas verdes y secas, pescados y caza;

- Evitar el fraude y engaño en pesos y medidas;

${ }^{14}$ M. Cuartas Rivero: op. cit. p. 251

${ }^{15}$ A.V.M. Manuscritos. N. ${ }^{\circ} 112$. Título de fielazgo, 1569. También, en A.G.S. Consejo y Juntas de Hacienda. Leg. 92. N. ${ }^{\circ}$ 98-132. 
- Inspeccionar las carnicerias y las plazas, las tiendas de especieros, drogueros y confiteros, asi como a los que vendiesen cera y pez, sebo y otras cosas para que en ellos no hubiera mercancias falsas o mezcladas;

- Obligar a guardar los aranceles y leyes a los taberneros, vinateros, bodegueros y mesoneros;

- Visitar a los menestrales y oficiales para que las obras fuesen correctas, así como hacer guardar las ordenanzas en la construcción de edificios por los particulares;

- Tener a su cargo y cuidado la limpieza y reparo de las plazas y calles públicas, puertas, entradas y salidas de la villa;

- Asistir e intervenir en las ordenanzas y repartimientos, juntamente con las personas a las que les estaba encomendado, a fin de que se hiciesen con justicia y sin agravios;

- Visitar los lugares de la Tierra e intervenir en todo lo tocante a dichas cosas, pero sin proveer a pedimiento de parte o de oficio, por corresponder este cometido al corregidor y su teniente;

- Conocer, pugnir y castigar a los que se excedieren o contravinieren lo dispuesto, aplicando las penas pecuniarias y corporales que correspondieren;

- Asistir a las reuniones del Regimiento con voz y voto, honras, gracias, mercedes, franquezas, libertades, preeminencias e inmunidades.

No caben muchos comentarios. Ante este cúmulo de competencias las reacciones no tardaron en surgir. Almonacid y Suárez se percataron inmediatamente de las suspicacias que despertaban sus actuaciones y denunciaron en el Consejo la intromisión de los regidores en sus competencias, así como las intenciones del Teniente que pretendía juzgar las denuncias él sólo y quedarse con los derechos ${ }^{16}$. Los diputados del co106. 1

${ }^{16}$ A.V.M. Ibidem. Sobrecarta del título de fielazgo del 16-XII-1569. A.G.S. Ibidem. Leg. 
mún impugnaron los títulos otorgados a los fieles ejecutores, alegando, en primer lugar, que sus atribuciones únicamente correspondian al Corregidor y a su Teniente, ya que en una ciudad como Madrid, sede de la Corte, eran muchos los abastos que entraban y la vigilancia debía de ser extrema, siendo tan sólo la autoridad del delegado regio habilitada para apresar a los transgresores y capaz de hacerles temer volver a delinquir $y$, en segundo lugar, que se limitaban a cumplir con el horario de las audiencias, establecian las condenaciones y cobraban las penas, lo cual fomentaba la delincuencia ${ }^{17}$.

En realidad, el origen de la oposición radicaba en que por este sistema se introducian en el gobierno local personas que quizá no poseian los requisitos fundamentales exigidos a todo regidor: Marcos de Almonacid, mercader, receptor de alcabalas y tercias hasta el momento de la compra de la fieldad, había recibido un regimiento por renuncia, que fue revocado por falta de calidades en el candidato; Suárez, tras desempeñar cometidos de poca relevancia en el Concejo, habia llegado a ser en 1569 procurador general de la villa, oficio que no le impedía dedicarse a sus viñedos en Aravaca ${ }^{18}$. En este sentido, son harto significativas las razones expuestas por el contador Galarza al corregidor, en 1569: por un lado, estos oficios privan a los regidores del ayuntamiento de hacer posturas de mantenimientos, lo cual vulnera sus preeminencias al conferirlas el monarca a otros individuos por nuevo contrato; por otro, porque al supeditar las actuaciones de los fieles de vara a las directrices de los fieles ejecutores, retraen a los caballeros hijosdalgo de la villa a ejercer aquellos oficios, con lo que no se encontrarán "personas decentes" que los sirvan, ni «de la calidad que han de ser conforme a lo que cerca desto se ha acostumbrado en esta villa de tiempo inmemorial a esta parte..." ${ }^{19}$.

El planteamiento no estaba exento de razón, pero había más: en ningún lugar de Castilla se podía vender oficios de justicia. Corregimientos, gobernaciones, alcaldias eran todos cargos de designación real ${ }^{20}$. El

17 A.V.M. Ibidem.

18 Sobre la revocación del regimiento de Marcos de Almonacid. A.V.M. Libros de Acuerdos, sesión de 9-V-1569. Sobre sus actividades, Archivo Histórico de Protocolos Notariales de Madrid (A.H.P). Protocolos 187 y 384. En cuanto a Nicolás Suárez, A.H.P. Protocolos 190, 192 y 392.

19 A.V.M. Libros de Acuerdos. Sesión del 19-XII-1569.

20 Sobre la venta de oficios de justicia, J. CAstillo de Bobadilla: Política para corregidores y señores de vasallos, Amberes 1704, 2 vols. (Ed. facsímil del I.E.A.L, Madrid 1978). T. II, p. 408. F. TOMAS y VAliente: op. cit., p. 162. 
Rey, al vender las fieles ejecutorias, estaba vendiendo jurisdicción y capacidad sancionadora, lo cual no era bien visto por las Cortes castellanas que consiguen en la convocatoria celebrada en Madrid en 1573 consumir los oficios de fieles ejecutores, quedando "en las ciudades y villas del Reino para que se sirvan, como se solia hacer, pagando los tales pueblos a los dueños de los dichos oficios el precio que justamente valieron al tiempo que se les quitaron, con que el salario que en penas de Cámara se da a los dichos fieles se consuma y quede consumido por Nos ..." ${ }^{20}$ bis. Madrid, entre otras ciudades, pudo consumir estos oficios en 1573. La operación costó a la villa 5.400 ducados, amén de los derechos que habían de pagar por los títulos que se despacharían para cada fiel ejecutor entrante, y del pago de los regimientos que hubieron de comprar para Almonacid y Suárez ${ }^{21}$.

El consumo de los oficios por el Ayuntamiento madrileño no supuso la desaparición de los fieles ejecutores, que prosiguieron en sus funciones, ni tampoco realzó a los fieles de vara, cada vez más dependientes de aquéllos. Estos, cuyo distintivo no era una vara de justicia sino un bastón de cinco palmos de largo ${ }^{22}$, iban acompañados normalmente por un portero y un escribano del Ayuntamiento, designados mensualmente por turno y sujetos a la prohibición de no desempeñar continuamente esta actividad hasta transcurridos dos años ${ }^{23}$.

En el juramento de sus cargos se comprometían a llevar los derechos del Arancel -es decir, los derechos que les correspondía por las denuncias efectuadas- y la orden de los señores fieles ejecutores en el uso y ejercicio de sus oficios; no podían hacer postura sin su licencia ni repesar el pan de los panaderos. Las causas y denuncias que hiciesen las debian asentar diariamente en el libro adecuado, rubricándolas todas, teniendo cuenta de las que hacian para que ni el escribano ni otra persona pudiesen cometer fraude. Los tres dia semanales en que se celebraban las audiencias en la Sala de la Cárcel, según estaba mandado por los fieles ejecutores y el Teniente de Ayuntamiento, debían acudir acompañados de su escribano, con la lista de las denunciaciones para asentarlas en el libro de la audiencia, no pudiendo cobrar ningún derecho

20 bis Nueva Recopilación. Ley XXII, t. III, libro VII.

21 A.V.M. Secretaría. Leg. 2306.24. Sobre las condiciones del consumo, Libros de Acuerdos, sesión del 20-X-1572. También en A.G.S. Consejo y Juntas Hacienda Leg. 124.1.

22 A.V.M. Secretaria. Leg. 2409.9. Real Provisión del 21-X-1502.

${ }^{23}$ Ibidem. Leg. 2409.12 y Libros de Acuerdos, sesión del 13-XII-1560. 
hasta que no estuviera visto por ésta. No podían tampoco condenar causa alguna ni mandar a nadie pagar cualquier tipo de efecto a sus porteros o escribanos e, igualmente, les estaba prohibido comer, beber o almorzar en casa de tratantes, así como recibir de ellos cosa alguna, tanto por vía de préstamo como de regalo ${ }^{24}$.

Normalmente recorrían las calles buscando aquello que pudiese ser objeto de sanción. En 1711, Manuel Alderete, fiel de vara, comprobó cómo a un carbonero de la madrileña calle del Carmen le faltaban determinadas pesas, al parecer imprescindibles para el despacho del género, engañando así a sus clientes, por lo que levantó de inmediato un acta del suceso que luego remitió a los regidores del repeso encargados de proveer lo más conveniente ${ }^{25}$. En otras ocasiones, no fueron las cosas así de pacíficas. Este mismo personaje durante la inspección rutinaria en una carnicería fue insultado y amenazado con un cuchillo por su dueña, lo que también le sucedió en la visita efectuada a los vendedores de pescado remojado ${ }^{26}$.

A tenor de lo expuesto, no parece un trabajo muy agradable o, al menos, muy cómodo. El aliciente suponemos que se derivaba de las cantidades que se podian embolsar, de manera más o menos legal, por el cobro de derechos. Para unos oficiales que no tenían salario fijo en el concejo, el producto de estas cantidades por fuerza debía ser de lo más rentable ${ }^{27}$. Esta sospecha se deduce de las quejas acerca de su actuación reflejadas en los Libros de Acuerdos, que la mayor parte de las veces se convierten en agravios en el juicio de residencia al que se debían someter al finalizar el cargo: «que los fieles de vara que ansi se nombran cada año por el dia de San Miguel den fianças legas, llanas y abonadas -5.000 maravedies - de haçer residençia y estar a derecho con los que dellos hubiere querellosos y pagar lo juzgado y sentenciado; y el corregidor que es o fuere desta villa o su teniente los tome residençia de como han estado y ejercido sus ofiçios, haciendo pregonar publicamente como se acostumbra hacer en las residençias, los dichos fieles assistan a ella personalmente treinta dias conforme a la ley." Este auto

${ }^{24}$ Ibidem. Leg. 2409.12 Auto del Corregidor D. Joan de Castro Castilla. Con relación al Arancel (7-XI-1565) al que debian someterse y la manera de aplicarlo: A.G.S., Consejo y Juntas de Hacienda. Leg. 106.1.

${ }_{25}$ Un resumen de las medidas de capacidad más corrientes en E. LORENTE TOLEDO: op. cit., p. 88.

${ }^{26}$ A.V.M., Secretaria. Leg. 2308.9.

27 A.V.M., Libros de Acuerdos. Sesiones del 7-II-1567 y 2-VII-1567. 
no agradó en absoluto a los fieles, los cuales en 1613, reivindicaron diversos puntos al respecto: no querían dar fianzas y no deseaban que se les tomase por separado la residencia sino con el resto de los oficiales y el corregidor. Su argumento consistia en que eran naturales e hijosdalgo de la villa y conocidos por los regidores, lo cual -según ellosera suficiente garantía. Además -continuaban-si se les tomaba de tal forma la residencia los tratantes contra quienes procedian lo utilizarian a modo de chantaje para delatarles en el juicio "teniendo así causa para no les dejar usar libremente el ofiçio". Creemos que de una manera solapada estaban descubriendo con su propio argumento cuál era el fondo de su "negocio". No obtuvieron resultado favorable, pues el Consejo, mediante auto de 1 de agosto de 1613, confirmó lo mandado sobre la toma de residencia ${ }^{28}$.

\section{EL ACCESO A LOS CARGOS}

Tras el consumo de los oficios de fieles ejecutores por el Ayuntamiento en 1573, éstos fueron designados por turnos mensuales entre los regidores, soslayándose asi posibles enfrentamientos entre ellos motivados no tanto por los salarios que conllevaba el cargo como por los beneficios que podrian obtener en su desempeño. Los fieles ejecutores tenían asignado en 1569 un sueldo de $6.000 \mathrm{mrs}$. anuales, cifra irrisoria en comparación con las sumas abonadas en la compra del oficio. Esta cantidad, desde 1573, fue aún más irrelevante, teniendo en cuenta que ahora se repartía entre doce regidores, lo cual les representaba tan sólo $500 \mathrm{mrs}$. El grueso de sus haberes procede, sin duda, de lo que perciben de las penas impuestas a los infractores -un tercio de su valor total pues los otros dos tercios se repartían entre los jueces y pobres de las cárceles ${ }^{29}$ - así como de la mitad de los derechos de las posturas y medidas ${ }^{30}$. Sobre este último aspecto hubo múltiples discrepancias y

${ }^{28}$ A través de algunas de las sesiones del concejo, se adivina cómo estos oficiales más de una vez fueron apresados por presuntas irregularidades: Ibidem. Sesiones del 27 de junio de 1565; 7 de febrero de 1567; 22 y 23 de junio de 1583; 2 de mayo de 1588 . Además, Leg. 2409.12. Las fianzas que debían dar figuran en la Sentencia de Montalvo, de la que nos ocupamos más tarde.

${ }^{29}$ A.V.M., Manuscritos. N. ${ }^{\circ} 112$.

30 Ibidem. Título de fielazgo 1569. 
poco a poco se van limitando las sumas que deben recibir por dicho concepto, sobre todo porque son muy superiores a las que cobraban los fieles de vara, según el Arancel de 1565, al que parecen tener que sujetarse, al menos desde 1571. Aún así, los Alcaldes de Casa y Corte se opondrán a esta práctica alegando el encarecimiento de los artículos de consumo de Madrid, lo cual es contestado por los fieles ejecutores, entre otras razones, porque sólo llevan por las posturas de los pescados frescos, caza, montería y otros géneros el valor en dinero de una libra al año por cada dos arrobas que se vendieren ${ }^{30}$ bis. La oposición de los Alcaldes de Casa y Corte no fue un hecho aislado. En las Cortes de 1573, se formuló una petición para que no cobrasen nada, aunque fuesen ellos los que establecian las posturas, a fin de que, únicamente, los percibiesen los fieles de vara. Igualmente, por parte de algunos regidores se intentaron suprimir estos derechos ya que - según decian- parecía que iban en interés particular. El acuerdo no gozó de la unanimidad y mucho menos de la simpatía del resto de los votantes por lo que no pudo prosperar ${ }^{31}$. Al final, sin embargo, un auto del Consejo les privará de esta pequeña ganancia, dando así cumplida satisfacción a quienes se oponían a ella: «los dichos regidores fieles ejecutores ansi dentro del ayuntamiento como asistiendo en las dichas carnicerías y rrepesos y fuera dellos de las posturas que hicieren de los pescados, puerco fresco, longaniza, frutas verdes y secas, vino, conserbas, confituras, miel, azúcar, turrones, aceyte, jabon y otros mantenimientos y cosas de qualquier genero suerte y nombre que sean que toca su postura al ayuntamiento y fieles ejecutores de esta villa, no puedan pedir, llevar ni recebir por si ni por sus mugeres, hijos, criados ni interpositas personas, direte ni indirete, cantidad alguna, mucha ni poca, de lo que ansi pusieren, ni dineros ni otra cosa de presente ni regalo, sopena que, si lo recibieren y llevaren, se proceda contra ellos (...), y que al tratante y otra qualquier persona que diere las dichas posturas y regalos se proceda contra él y pague quatro ducados... ${ }^{32}$.

Por el mismo auto, se establecia que únicamente podrían cobrar los derechos a que nos venimos refiriendo los que asistiesen a las audiencias. Las condenaciones se imponían siguiendo un arancel ${ }^{33}$. Asimismo, y según la referida tasa, se castigaba con cuatro reales a los que vendie-

30 bis A.G.S., Consejo y Juntas de Hacienda. Leg. 106.1.

${ }^{31}$ Petición VI de las Cortes de 1573, se remite el asunto al dictamen del Consejo. Sobre ello, A.V.M. Libros de Acuerdos. Sesiones del 26-V-1589 y 29-V-1589.

32 A.V.M., Manuscritos. N. ${ }^{\circ} 112$. Novisima Recopilación. Ley I, t XVIII, Libro III.

33 Ibidem. 
ren sin postura antes del pregón; a los que no sellaren los pesos y medidas en el plazo fijado, también se les sancionaba con cuatro reales; si se comprobaba que los dichos pesos estaban manipulados, la pena ascenderia a seis reales. Para el reincidente, éstas eran algo más severas: la primera vez, pagaría ocho veces la sanción original; la segunda, dieciséis veces; y la tercera, veinticuatro, siendo, además, condenado a destierro por cuatro años y exhibido públicamente, para ejemplo de otros, con las pesas y medidas al cuello ${ }^{34}$.

Si la designación de los fieles ejecutores apenas revistió conflicto, no se puede afirmar lo mismo en el caso de los fieles de vara. Cada 29 de septiembre, previo aviso personal de los porteros del Concejo a cada uno de los regidores, se juntaban en la sala del Ayuntamiento para llevar a cabo la elección de dos fieles de vara, dos alcaldes de hermandad, un procurador general, un mayordomo de propios, un contraste, un marcador de pesas, vara y aceite, tres alarifes, dos apreciadores, un marcador de tierras, un sello, un guía y seis caballeros de monte. Desde este preciso instante comenzaban las controversias, ya que el Corregidor, como presidente de la sesión, determinaba qué regidores podian votar: únicamente se permitía hacer uso de esta atribución a aquellos que hubiesen asistido a la mitad de las reuniones del cabildo celebradas en el año. No cuesta imaginar las discordias que se generaron, especialmente si tenemos en cuenta que algunos de los capitulares desempeñaban simultáneamente cargos reales, lo cual - según ellos - les impedia la asistencia requerida. Una vez aclarada esta cuestión - perfectamente podian transcurrir más de dos o tres sesiones en ello- se recibia juramento, "en forma de derecho", de hacer la elección conforme a la Sentencia de Montalvo y la Concordia de Bobadilla.

La Sentencia del Licenciado Alfonso Díaz de Montalvo, pronunciada el 7 de enero de 1454 por orden del Rey Juan II, al hilo de los conflictos que habían surgido entre los regidores de Madrid y los caballeros y escuderos de la villa por obtener la primacia en los comicios, regula su designación de manera escrupulosa por ser la fieldad "oficio de gran cargo, según el poderío que los dichos fieles han por ordenanzas de la dicha villa e lo perteneçer homes entendidos e honrados". Los oficios habrían de ser elegidos por los regidores anualmente; los candidatos debian proceder del estado de los caballeros y escuderos de la villa así

${ }^{34}$ Ibidem. 
como ser vecinos de Madrid ${ }^{35}$; no podían ser "continos ni comensales en casas de los regidores ni otros caballeros de la villa"; estaban obligados a servir por sí mismos los oficios y se les impedía delegar persona en su lugar; no era posible la reelección "de guisa que todos los que fueren pertenesçientes goçen de los dichos ofiçios e no vuelvan a los que primeramente los tuvieron (...) hasta que la tanda sea acabada por las colaciones entre aquellos caballeros escuderos que los regidores entendieren..." ${ }^{36}$.

Las apelaciones a esta Setencia fueron numerosas. No se cumplió de manera estricta y es por ello por lo que el corregidor de Madrid, Juan de Bobadilla, el 6 de septiembre de 1477, se vio obligado a desarrollar algunos puntos de la anterior y a dictar otros nuevos. Aquí nos referiremos tan sólo a los que modifican de algún modo a los ya enumerados. El aspecto fundamental a partir de ahora es que todos los oficios se repartirán por tandas en doce colaciones, hechas dos cuadrillas:

\section{Cuadrilla 1}

Santa María

San Nicolás

San Juan y San Miguel

Santiago

Santa Cruz y S. Sebastián

San Andrés

\section{Cuadrilla 2}

San Justo

San Miguel de los Otoes

San Salvador

San Martin

San Pedro

San Ginés

${ }^{35}$ Sobre la reserva de determinados oficios para los hijosdalgo, se pueden consultar entre otros trabajos: J. I. GutiéRREZ NIETO: «Limpieza de sangre y antihidalguismo hacia 1600" Homenaje a Juan Reglá, Valencia 1975, pp. 497-514. V. CADENAS y VICENT: "De la posesión y propiedad de la hidalguia", Hidalguia. No. 75, 1966, pp. 147-150. Del mismo autor "Los oficios y la hidalguía", Hidalguia No. 81, 1967, pp. 149-154. A. Dominguez Ortiz: Las clases privilegiadas en el Antiguo Régimen, Madrid 1973, p. 31. Algunas de las pruebas de hidalguía las encontramos en A.V.M., Secretaría, Leg. 1-18-23. Manuscritos, No. 112. Sobre ello, mi trabajo "Hidalgos y pecheros en el Antiguo Reino de Toledo. La mitad de oficios concejiles en la comarca de Quintanar de los siglos XVI y XVII", Anales Toledanos. (En prensa). Sobre la vecindad y naturaleza de los candidatos a cargos municipales, véase J. Garcia MARín: La burocracia castellana bajo los Austrias, Sevilla 1976, p. 302. A.V.M. Manuscritos No. 112.

${ }^{36}$ A.V.M. Secretaria. Legs.: 2355.12, 13, $14 ; 2184.78 ; 2303.8 ; 2253.19$. 
Los regidores deberian echar a suertes entre ambas cuál gozaría primero de los oficios, y a la que cupiere la suerte los obtendría por completo; el segundo año la otra cuadrilla; el tercer año tornaría de nuevo a la primera y asi sucesivamente. Dentro del grupo agraciado, los oficios habrian de ser repartidos entre las distintas parroquias o colaciones, siendo para cada una de ellas un oficio, y la mayordomía, procuración y guía sorteadas entre las seis. Las tres que no hubiesen sido agraciadas los ostentarían el año inmediato.

La vispera de San Miguel el escribano del concejo recibiría un escrito de cada colación por el que se relacionaba los caballeros escuderos "perteneçientes e sufiçientes", debiendo mostrar dicha relación a los regidores en el momento de las elecciones, "proveyendo más a los dicho oficios que las personas para el bien e procomún de la villa». Si alguna colación no cumpliese este trámite o dejase de poner a algún vecino, serían los regidores los que determinarían por suertes los candidatos. Se observa, pues, el amplio poder depositado en los regidores para un acto de tanta relevancia en la vida municipal como son los comicios. En caso de ausencia, el oficio se proveía en otra persona de la misma parroquia. Los que se mudaran a otra colación una vez disfrutado éste, no podrian volver a entrar en suertes. Asimismo, no se permitía aceptar carta real para disfrutarlo ${ }^{37}$.

Estrictamente estas eran las condiciones a las que debian someterse los candidatos. El cargo despertaba pasiones y no fue tan fácil conformarse con lo dispuesto en las ordenanzas, y mucho menos, con las irregularidades desatadas en las elecciones protagonizadas o propiciadas, algunas veces, por los propios regidores - no olvidemos que eran ellos los que elegían-y alentadas, otras, por los propios interesados a los que no les había sido favorable la suerte.

Al amparo de esta normativa, en 1564, Pedro de Herrera, regidor de Madrid, revocó las elecciones de la parroquia de Santa María porque el elegido no se encontraba en la villa. Pese al falso juramento de su suegro, para colmo procurador del número de la villa, que insistia en decir que su yerno estaba enfermo en Torrejón de Velasco, finalmente se descubrió que hacía más de dos meses que habia marchado a Murcia. D. Pedro de Vozmediano, otro regidor, denunció al Teniente de Corregi-

\footnotetext{
37 Ibidem.
} 
dor que presidía aquella reunión por dilatar el proceso electoral. Todo parecía ir encaminado a impedir que saliese elegido el otro candidato, Gregorio de Vega. Como las discrepancias iban en aumento, Juan de la Concha aprovechó para reclamar también su candidatura. Vozmediano alegó que no habia probado su hidalguía; los otros regidores dijeron que si lo había hecho. La mano de un niño fue la encargada de dirimir el conflicto. La suerte le cupo a Juan de la Concha ${ }^{38}$.

Podía ocurrir que elementos ajenos al concejo interfiriesen la buena marcha de los comicios. El cura de San Salvador había dado por parroquianos a cuatro individuos. Algo le empujó a rectificar su testimonio. Para sorpresa de todos, se personó en la Sala del Ayuntamiento, manifestando que uno de ellos, Andrés de Rojas, no lo era; lo había incluido en su certificación por presión del vicario de la villa a quien le bastaba lo hubiera sido durante ocho meses. No obstante, le permitieron entrar en suertes, resultando reprobado. En su lugar, salió Luis de Valdés, alcaide de la Cárcel, al menos en 1583, de lo que se desprende que no existía incompatibilidad en este tipo de oficios ${ }^{39}$. En ocasiones, sin embargo, el haber ocupado otro puesto en el concejo, fue utilizado como baluarte para interrumpir el proceso. Tal fue el caso de Pedro Ruiz de Tapia, recusado en 1578 al corresponderle la fieldad por la parroquia de San Justo, ya que no había presentado las cuentas de su ejercicio como mayordomo del pósito de Madrid y quedaban pendientes de cobro muchas cantidades. No se admitió el argumento; Tapia aceptó y juró el cargo $^{40}$.

La villa, en sus sesiones de gobierno, siguió perfilando los requisitos establecidos hacia ya más de un siglo. Un aspecto que acaparó el interés de los regidores fue el disponer con la antelación suficiente informes de las personas que pudiesen ostentar los oficios de fieles de vara, a fin de evitar impugnaciones una vez realizados los comicios. Así, en 1600 se dispuso que en el plazo de dos meses anteriores a la fecha establecida para los nombramientos, el parroquiano más antiguo diese testimonio de

38 A.V.M. Manuscritos. No. 132. Elecciones de oficios año 1564.

39 Ibidem. Elecciones de oficios año 1583. Conocemos otros casos de compatibilidad: en 1569, por la parroquia de Santiago, Luis Hurtado era veedor de las obras de Su Majestad; en 1568, por la de Santa Cruz, Pedro Ortiz, era portero del Consejo; en 1608, por la parroquia de Santa María, Pedro Lorenzana, era criado de Su Majestad; en 1617, por la de San Gil, Juan Díaz de la Concha, era macero de honor de Su Majestad. Secretaría Leg. 1.412.3.

${ }^{40}$ Ibidem. Elecciones de oficios, año 1578. 
las personas interesadas en los cargos ${ }^{41}$. No obstante, en 1613, los regidores elevaron un acuerdo al Consejo que se resume en estas propuestas:

1. En el primer ayuntamiento del mes de septiembre se habrían de sortear las parroquias a fin de que los curas gozasen de tiempo suficiente para inquirir las calidades de los idóneos, debiendo enviar unas memorias cerradas a los escribanos del ayuntamiento en el plazo de ocho dias. Estas memorias se habrian de discutir en el seno del mismo y los pretendientes deberian darse a conocer para que se supiesen "sus calidades y entretenimientos";

2. Las informaciones de hijosdalgo, habrían de ser de padres y abuelos; en los lugares donde hubiese "pechería" presentarian una fe de que no pechan;

3. No podría ser fiel de vara aquel que hubiere tenido o tuviere oficio mecánico, ni tienda pública hasta pasados cuatro años después de haberlo dejado ${ }^{42}$;

4. El candidato habria de ser vecino y natural de la villa o casado con hija de natural. No siendo así, se le exigiría el estar avecindado por un periodo mínimo de diez años y demostrar haber vivido durante tres en la parroquia por la que se presentase;

5. Si se comprobara que había habido engaño por parte del designado y constase por información de testigos, la villa podria volver a echar suertes metiendo en el cántaro las papeletas de los que estuviesen calificados ${ }^{43}$.

${ }^{41}$ A.V.M. Libros de Acuerdos. Sesión del 7-X|-1600.

${ }^{42}$ Sobre esta cuestión, J. A. Maravall: Estado Moderno y Mentalidad social, Madrid 1972, t. II p. 22. B. Gonzalez Alonso: Sobre el Estado y la Administración de la Corona de Castilla en el Antiguo Régimen, Madrid 1981, p. 71. A. DOMinguez ORTIz: Instituciones y Sociedad en la España de los Austrias, Madrid 1985. p. 23. Y mi trabajo "Conflictos sociales en torno al régimen municipal manchego. Las elecciones de oficios concejiles en la Comarca de Quintanar bajo los Austrias". Cuadernos de Estudios Manchegos. (En prensa.)

${ }^{43}$ Cipriano de Salazar, regidor de Madrid en el año 1613, recusa al fiel elegido por engaño " $y$ ansi quando entró en el ayuntamiento a jurar el dicho corregidor $y$ regidores se admiraron de que se les hubiese engañado por la poca edad y persona para un ofiçio tan grande sera perderlo el respeto... y el dicho corregidor le hiço echar fuera diciendo que habia sido engañado y que no habia de consentir se hiçiese tal nombramiento...". A.V.M. Secretaria. Leg. 1.18.23. 
6. El que resultase reprobado, no habría de ser tenido en cuenta de nuevo, ni el corregidor lo habría de permitir ${ }^{44}$.

Pese a estas disposiciones las rivalidades del siglo XVII tuvieron características análogas, toda vez que nos encontramos a personajes ya conocidos en la vida municipal pugnando por el oficio, lo cual delata el interés que tenían porque recayese en individuos de su familia, despojándolo así, y en la práctica, de su primitivo contenido, es decir, que pese a ser electivo, y por tanto contingente, se intentaba acaparar en unas pocas familias que asi lo fiscalizaban. En este sentido, cabe recordar los argumentos esgrimidos por Andrés de Rojas, aspirante al oficio en 1622, donde resalta que sus antepasados ya lo habian desempeñado con acierto mientras que el elegido, Rodrigo de Monzón -apellido también de raigambre en el Concejo- no tenía probada su vecindad en la villa. Su demanda, plenamente justificada, fue empero rechazada, pues al final resultó designado su antagonista, posiblemente apoyado por un sector importante de los regidores vinculados a la familia ${ }^{45}$. En 1637, nos encontramos con un caso de parecidos rasgos en el que interviene el propio corregidor, adelantando la hora de la reunión para así excluir a ciertos capitulares de la elección y poder nombrar al candidato del grupo contrario, emparentado con don Luis de Montenegro, regidor, que gozaba además del apoyo del procurador general ${ }^{46}$.

\section{CONFLICTOS JURISDICCIONALES}

La puesta en práctica de las competencias expuestas en el primer apartado, provocarán de inmediato conflictos con los representantes reales. Por un lado, con el Corregidor y su Teniente en cuanto que ambos

44 A.V.M. Secretaría Leg. 2409.12. Manuscritos Nos. 39 y 112. Auto del Consejo de 1613. Posteriormente, el 9-IX-1620 confirmó el Consejo un auto, a excepción del capítulo que se refería a los oficios mecánicos. A.V.M. Secretaría Leg. 2409.12.

45 Ibidem Leg 2409.16. Finalmente fue reconocido como fiel Rodrigo de Monzón, Leg. 2409.12. No sirvieron de mucho los argumentos de Rojas, pese a que sabemos que era cierta la vecindad que alegó, gracias al testimonio de J. Álvarez y BaEnA: Hijos de Madrid ilustres en Santidad, dignidad, armas, ciencias y artes, 4 vols. Madrid 1789-1791. t. 1. p. 97.

${ }^{46}$ Ibidem Leg. 2409.21. 
tenían un papel importante en las condenaciones a los infractores de la normativa municipal que regulaba los pesos, medidas y precios; por el otro, con los Alcaldes de Casa y Corte que se inmiscuian en las funciones de los Fieles Ejecutores a la hora de fijar los precios.

\section{1) Corregidores y Tenientes}

La autoridad del Corregidor en el Ayuntamiento es algo que no plantea duda. Castillo de Bobadilla lo define perfectamente: "es el mayor después del Príncipe de la República" ${ }^{47}$. Sus atribuciones, en términos generales, se circunscribieron a tres aspectos: restablecimiento y defensa de la paz pública, administración de justicia y gobierno municipal ${ }^{48}$. Para su ejecución contó con el auxilio principal del Teniente, siempre letrado, que le asesoraba en materias de justicia y que gozaba de la confianza absoluta del Corregidor puesto que de él dependía su nombramiento ${ }^{49}$.

En esencia, la necesidad de crear los oficios de Fieles Ejecutores se justificaba por la urgencia de aliviar, en cierta medida, al Corregidor de una parte de las tareas de su ministerio. No obstante, para evitar posibles abusos de aquéllos, se estableció un juzgado de fieles en el que estuviese presente el Teniente de Corregidor. Desde este mismo instante, surgen los memoriales de agravios entre ambas instancias, pues éste, según lo denunciaron Almonacid y Suárez al poco tiempo de ocupar sus cargos, trata de evitar que participen en los juicios incoados y, por consiguiente, apropiarse de la parte que le correspondía por las penas impuestas. La situación apenas se modifica en años sucesivos como se deduce de las peticiones de la villa exigiendo se le guarde lo provisto en los títulos de venta de los oficios. En 1582, incluso, se presenta una petición en las Cortes solicitando que no se entrometa la justicia ordinaria en sus competencias ${ }^{50}$. Meses más tarde se comisiona a dos regidores,

47 J. Castillo de Bobadilla: op. cit., t. I. p. 18. La bibliografía sobre la figura del corregidor es abundante, a modo de ejemplo: B. GONZÁLEZ ALONSO: El corregidor castellano. 1348-1808, Madrid 1970. L. Garcia de ValdeAVELLANO: Curso de historia de las instituciones españolas de los orígenes al final de la Edad Media, Madrid 1977. A. Bermúdez AzNAR: El corregidor en Castilla durante la Baja Edad Media, 1348-1474, Murcia 1974. F. ALBI: EI corregidor en el municipio español bajo la monarquia absoluta, Madrid 1943.

48 B. GonzÁlez Alonso: Gobernación y gobernadores, Madrid 1974. p. 118.

49 B. GonzÁlez Alonso: El corregidor... p. 165.

50 A.V.M. Libros de Acuerdos. Sesión del 15-1-1582. A.G.S. Consejo y Juntas de Hacienda. Leg. 106.1. 
Marcos de Almonacid y Gilberto de Bedoya, para que traten en el Consejo el mismo problema ${ }^{51}$. En 1589, las discusiones en el seno del Ayuntamiento van tornándose más duras a causa de las atribuciones que cada una de las partes se quiere arrogar. El Dr. Liébana, Teniente de corregidor, habia ordenado que los fieles ejecutores, en adelante, no hiciesen condenaciones de «los pesos faltos de la carne, medidas y otras cosas en que incurren los que venden mantenimientos sino que todas ellas las envien y denuncien en el dicho Teniente" ${ }^{52}$. Este malestar generó un pleito importante en 1596 entre el procurador general de la villa y Pedro de Tapia, fiscal de su Majestad. Los agravios de los regidores fieles ejecutores eran precisos: se les apartaba progresivamente de sus cargos, no reconociéndoles lo expresado en sus nombramientos; esto es, acusaban al Corregidor y al Teniente de que sólo se les permitía intervenir en las causas denunciadas por ellos y no en las incoadas por los fieles de vara, porteros y otras personas. Los Tenientes defendian sus pretensiones alegando que toda la jurisdicción que aquéllos reclamaban les habría costado mucho más de lo que pagaron por sus títulos; que siendo la Corte tan grande eran muchos los negocios a resolver y la aplicación de la justicia no podía retrasarse, lo que sucedería de comisionarse los delitos a las reuniones del juzgado previsto por los títulos; que al estar el dicho juzgado formado por el Teniente, dos fieles y un regidor, el voto del primero era ineficaz, porque siempre estaría en minoría respecto al resto, ya que ellos, al ser vecinos de la villa, "templarían las condenaciones, por tener gratos [a] los tratantes y vivanderos para la provisión de sus casas, de manera que jamás se castigaría cosa alguna como conviniese", sin embargo él, por ser "forastero y temporal su oficio, y dar residencia de él, pretendía, con servirlo bien, merecer otras cosas mayores"s ${ }^{53}$.

La animadversión suscitada por el Teniente no dependía tanto de la intromisión de la justicia ordinaria en las prerrogativas de los fieles ejecutores - continuamente reconoce el ayuntamiento su superioridadcomo de un problema de indole económica. Considerando que los salarios de los oficiales no eran demasiado elevados ${ }^{54}$, los maravedis que el teniente podia obtener por las penas de condenaciones le ayudaban a subsistir de manera más honrosa y desahogada, mucho más, sin duda,

51 A.V.M. Libros de Acuerdos. Sesión del 10-X|-1582.

52 Ibidem. Sesión del 29-V-1589.

53 A.V.M. Manuscritos. N. ${ }^{\circ} 112$. Título de fielazgo de la villa de Madrid.

54 El salario para el corregidor de Madrid en 1597, por ejemplo, era de unos 140.000 mrs.; el Teniente recibía 10.000. A.V.M. Contaduria Leg. 1422.1. 
si lograba excluir de las mismas a los fieles ejecutores. De ahí que una de las alegaciones expuestas por ellos en su defensa fue que si se admitia a los fieles en los juicios no incoados por ellos se reducirían sus ingresos, de suerte que "resultaría mucho daño al bien público, porque faltando el dicho aprovechamiento a los tenientes, que era el mayor que tenía en el dicho oficio, vendría mucha disminución, de manera que no se hallarían personas que le quisieren servir de las letras y partes que se requeria" ${ }^{55}$. Aunque el Consejo se pronunció a favor de los fieles ejecutores, instando a ambas partes a guardar lealmente lo dispuesto por el Rey en el momento de la creación de los polémicos cargos ${ }^{56}$, esto no sirvió para acallar el conflicto. En 1601, Juan Fernández, regidor de Madrid, partía a Valladolid, comisionado por el concejo, con el fin de tratar sobre el asunto en la Chancilleria ${ }^{57}$. Sus demandas no debieron ser admitidas como tampoco su petición para que el Corregidor ocupase el lugar de los Tenientes en los juzgados, obviando así sus frecuentes abusos ${ }^{58}$. Tras varias consultas del Consejo de Castilla en 1620 y 1621, Felipe III decreta que los Tenientes de corregidor asistan con los fieles ejecutores en las audiencias que han de celebrarse cada semana los martes, jueves y sábados en la Sala de visita de la Cárcel de la villa e impongan las condenaciones como hasta la fecha han venido realizándose». 59

Pasarian algunos años todavía antes de que la Corona aceptase la sustitución del Teniente por el Corregidor, según los requerimientos de la villa. La primera concesión se hizo en 1624, pero fue en 1629 cuando una Real Cédula se pronunció a favor de los Corregidores ${ }^{60}$. Las nuevas disposiciones y el paso del tiempo no contribuyeron a evitar la polémica.

${ }^{55}$ A.V.M. Manuscritos, N. 112. Alegación de los diputados del común contra los fieles ejecutores.

${ }_{56}$ Ibidem. Autos del Consejo de 22 de noviembre de 1598 y del 28 de noviembre de 1600 y Ejecutoria del 14 de diciembre de 1600, Novisima Recopilación. Ley II, t. XVIII, libro III.

57 A.V.M. Secretaria. Sesión del 3 de septiembre de 1601.

58 A.V.M. Libros de Acuerdos. Sesiones del 16-V-1612; 21-V-1612; 13-VI-1612; 9-VII1612.

59 A.V.M. Manuscritos. N. ${ }^{\circ}$ 112. Novisima Recopilación. Ley I, t. XVIII, libro III.

${ }^{60}$ Ibidem. Leg. 3404.40, el 30 de enero de 1624, se le concede licencia al corregidor de Madrid, D. Juan de Castro y Castilla para asistir junto a los tenientes al juzgado, sin llevar parte alguna de las condenaciones. Sin embargo, años más tarde, por Cédula de 7 de marzo de 1629 se les atribuía plenamente esta competencia: ello coincidía con el servicio al Rey de los 18 millones de ducados, establecido en las Cortes del mismo año: A.V.M. Manuscritos, N. ${ }^{\circ} 112$. En la Ley II, t. XVIII, libro III de la Novísima Recopilación, se fecha esta Real Cédula en 7 de marzo de 1669. 
Esta surgía siempre cuando, por cualquier circunstancia, la máxima autoridad del gobierno municipal estaba ausente de la villa o era sustituida provisionalmente por su Teniente. En 1773, un fiel ejecutor se sintió muy molesto por la actuación del Corregidor interino D. Juan Palanco, quien - según denunciaba el agraviado- tras desalojar el Juzgado del Repeso, impidiendo sus deliberaciones, y sancionar con 10 ducados al escribano, se había apropiado del importe de las multas que el ejecutor tenía depositadas. Palanco acusó al denunciante a su vez de fraude y abuso de poder. Los argumentos utilizados por uno y otro para su defensa eran los de antaño. EL Consejo resolvió dar la razón a los regidores, apoyándose en todos los autos que desde 1569 y a lo largo del siglo XVII, se habían expedido ${ }^{61}$. Todavía en 1804 la cuestión estaba sin resolver de forma definitiva pues, en esta fecha y ante una denuncia presentada por un regidor de Madrid, se reiteran los decretos anteriores prohibiendo a los Tenientes intervenir en los asuntos tramitados por el Juzgado de fieles ejecutores en el cual no tiene voz ni voto salvo que sustituyan, por ausencia, al Corregidor que es el único legítimamente autorizado a participar en sus reuniones ${ }^{62}$.

\section{2) Alcaldes de Casa y Corte}

Otro punto de conflicto surge con los Alcaldes de Casa y Corte por un motivo distinto aunque relacionado con el anterior: la postura de los mantenimientos. Ya hemos visto cómo los fieles ejecutores de cada ciudad - en definitiva el Concejo- tenían la facultad de establecer los precios de los géneros que consumían sus vecinos y, también, de proceder judicialmente contra los infractores, remitiendo los asuntos al Juzgado de fieles ejecutores, en el que asistían junto con el Teniente de corregidor. Tales facultades, sin embargo, son cuestionadas cuando el Rey se instala en una población determinada, pues los Alcaldes de Casa y Corte tienen asignadas competencias a la hora de determinar los precios de los artículos que se van a consumir. Las protestas de los Concejos no impedirán que los Alcaides prosigan en sus funciones, perfectamente reguladas por la Pragmática dada en Zaragoza el 20 de mayo de 1518 por Carlos I, reiterada en 1528, 1532, 1539 y confirmada por el Consejo de Castilla en su Auto de 11 de noviembre de 1551:

61 A.V.M. Secretaría. Leg. 2308.9, Auto del Consejo de 7 de marzo de 1782.

${ }^{62}$ Novisima Recopilación. Ley II, t. XVIII, libro III. 
“... los nuestros Alcaldes de Corte o alguno de ellos, por sí mismos pongan los precios del pan, vino y cebada, y paja y carnes, y caza y aves, y otros mantenimientos que se traxeren a vender a nuestra Corte de fuera parte, informándose de los fieles y regidores de la Ciudad, villa o lugar donde estuviere nuestra Corte, del precio de las cosas que ansi hubieren de poner, para que más justamente los pongan" ${ }^{63}$.

Mientras la Corte fue itinerante los conflictos entre los regidores y los Alcaldes no debieron tener consecuencias graves ni alterar el normal desarrollo de la vida ciudadana. El problema nace cuando ésta se establece con carácter definitivo en Madrid. Ya en 1551 los regidores se habian quejado de quedar postergados en las posturas de los mantenimientos de la villa, sin demasiado éxito. Algunos años después, insistirán en sus demandas, como se desprende de la siguiente solicitud dirigida al Monarca:

“... por quanto esta villa siempre tuvo el govierno de todo lo tocante a posturas de mantenimientos de todo genero y los Alcaldes de esta Corte se an yntroducido de algunos años a esta parte en quitar a esta villa muchas cossas de las que le a tocado y toca y algunas posturas de mantenimientos, su magestad se sirva de haçer merçed a Madrid que de aqui adelante las posturas de todos los generos de bastimentos suyos y que se binieren a vender a Madrid (...) las haga la villa sin que los Alcaldes se entrometan (...) sin que tengan ninguna jurisdicción en ello ni por apelación, porque las apelaciones ayan de ser al Consejo, a la Sala de Gobierno donde aya de tocar y toque su conocimiento, con inhibición de la dicha sala de Alcaldes..." ${ }^{64}$.

Sus reclamaciones no debieron tener eco alguno, sobre todo cuando pretendían despojar a los Alcaldes de sus atribuciones para reasumirlas, no obstante conservar las posturas de algunas carnes (cerdo, por ejemplo), de todos los pescados, frutas y conservas así como de los azúcares y sus derivados, sin olvidar cierta participación en los precios al por menor, según se deduce de la solicitud planteada en 1561 por los herederos

63 Ibidem. J. Fayard: Los miembros del Consejo de Castilla (1621-1746), Madrid 1982. Pp. 23 y 75. Mediante Pragmática de 1583, el Rey establecía en Madrid seis alcaldes de Casa y Corte: Biblioteca Municipal de Madrid. Mb. 2047. Sobre el desarrollo de estos personajes nos ilustra perfectamente A. DOMÍnguez OrTIZ: “Aspectos del vivir madrileño durante el reinado de Carlos Il', Anales de Estudios Madrileños, t. VII, 1971, pp. 229-252.

${ }^{64}$ A.V.M. Secretaría. Leg. 1160.52. 
de las viñas de Madrid para que el concejo rebaje dos maravedís el precio al por menor de lo que vendieren, a fin de poder competir con los vinos traídos de otras localidades y tasados por los Alcaldes en 20 maravedís la azumbre ${ }^{65}$.

Esta dualidad en la fijación de las posturas será un motivo continuo de conflictos, ya que los Alcaldes tratan de ampliar sus cometidos a expensas del concejo que, también, aspira a ampliarlos a su costa. En 1573, sabemos que los fieles deciden bajar el precio de los pescados negándoles los Alcaldes esta posibilidad bajo multa de 200 ducados. Seis años más tarde se lamentan del "gran desorden e inconveniente" que se observa en la materia por no existir coordinación entre ambas instituciones. En 1581, Marcos de Almonacid es apresado por bajar el precio de los melones, presentando una querella por este hecho al presidente del Consejo de Castilla. En 1582, solicitan que se observe el punto relativo a que los Alcaldes se reúnan con los fieles ejecutores para fijar semanalmente los precios de los bastimentos así como de los pescados frescos de mar y río, aves y caza ${ }^{66}$.

El momento de máxima rivalidad lo encontramos hacia 1585 , cuando la Sala de Alcaldes de Casa y Corte dicta un Pregón de Buen Gobierno por el cual se reglamentan muchas de las actividades del municipio, sin contemplar, en modo alguno, a los fieles ejecutores ${ }^{67}$. A este hecho hay que sumar su progresiva tendencia a interferir en la postura de aquellos artículos sobre los que el concejo tenía facultades exclusivas. Así, en 1589, los regidores elevan una queja al Consejo de Castilla y su Presidente solicitando que los Alcaldes se inhiban de tasar los pescados frescos y escabeches porque vulneran la costumbre y práctica seguida hasta entonces ${ }^{68}$.

Ignoramos cuál fue la respuesta del Consejo a la petición, pero sabemos, por el contrario, que estos conflictos, y el desconcierto que provocaban, no pasaron desapercibidos motivo por el cual el 4 de mayo de 1590 se instituye la Junta de Policía, compuesta por el Presidente y dos

${ }^{65}$ A.V.M., Libros de Acuerdos. Sesión del 9-VII-1561.

${ }^{66} \mathrm{Ibidem}$. Sesiones del 7 de febrero de 1573; 9 de septiembre de 1579; 19 de julio de 1581; 10 de noviembre de 1582, 11 de mayo de 1594.

${ }_{67}$ Archivo Histórico Nacional. Consejos. Libro 1197 folio 160, lo encontramos también en A. Gonzalez DE AMEZUA: "Las primeras ordenanzas municipales de la Villa y Corte (1585)" Revista de Bibliotecas, Archivos y Museos, 12, III. Madrid 1926. p. 413.

${ }^{68}$ A.V.M. Libros de Acuerdos. Sesión del 13-II-1589. 
ministros del Consejo de Castilla, un Alcalde de Casa y Corte, un Fiscal, el Corregidor, un regidor y un escribano del Ayuntamiento, a quien se encarga tanto el ornato, seguridad e higiene de la villa como la provisión de mercancías ${ }^{69}$. Sus actuaciones no consiguieron erradicar los problemas ya mencionados. Entre 1590 y 1599 aparecen registrados nuevos memoriales de agravios presentados al Consejo por la villa. Recordemos, entre otros, el formulado en 1594 por el fiel ejecutor Félix Vallejo quien, habiendo ido a proceder contra algunos carniceros que vendían cabrito de mala calidad $y$, por tanto, susceptible de ocasionar enfermedades, había sido apresado por los Alcaldes, quedando impunes los infractores ${ }^{70}$. Hacia 1599 , la Junta de Policía se limita únicamente a procurar la seguridad y la higiene de la villa, absteniéndose de las cuestiones relacionadas con el abasto ${ }^{71}$.

La pugna entre los regidores y los Alcaldes comienza a remitir desde 1621 y 1622, en que las atribuciones de los fieles ejecutores aparecen definidas con alguna precisión, si bien no sucede lo mismo con las de los Alcaldes de Casa y Corte ${ }^{72}$. De este modo se venía a poner un poco de orden en la postura de los mantenimientos, evitando irregularidades que sólo perjudicaban a los vendedores y a los consumidores ${ }^{73}$.

Aún así, lo cierto es que los conflictos de competencias entre ambos organismos no cesaron por completo, surgiendo en aquellos casos en que los géneros no se correspondian de manera clara con los que unos y otros debian tasar. En 1645, el enfrentamiento se suscita por la postura del chocolate, reclamada por los Alcaldes ${ }^{74}$. En 1665, sucede los mismo con las fresas, recibiendo los regidores un auto de la Sala notificándoles no procediesen a su postura bajo pena de doscientos ducados, lo cual es contestado por el concejo que denuncia esta intromisión al Consejo, reivindicando «la costumbre y posesión de tocarle y haber dado esta postura los años pasados", aparte del malestar generado por el trato recibido, ya que, en palabras del procurador general de la villa, no se les

69 A. GonzAlez DE AmezUA: "El bando...". p. 151.

70 A.V.M. Libros de Acuerdos. Sesión del 11-V-1594. Memoriales de agravios de la villa, por idéntico motivo, presentados al Consejo en sesiones del 27-VI-1590; 14-III-1592; 22-I-1596; 11-IX-1599.

7 A.V.M. Secretaria. Leg. 3405.7, consulta hecha por la Junta de Policía al Rey el 22. XII-1599.

${ }^{72}$ Novísima Recopilación. Ley II, t. XVII, libro III.

${ }^{73}$ A.V.M. Secretaria. Leg. 2308.9, folio 16.

${ }^{74}$ A.V.M. Libros de Acuerdos. N. ${ }^{\circ} 31$, folio 58 vto. 
había otorgado la decencia y estimación que merecian por sus oficios, puesto que no habian obrado por sí, sino en nombre de la República, se les había considerado como a tratantes, "punto de mucho dolor y sentimiento cuando por sus oficios tienen igual jurisdicción». El auto de 18 de mayo reconoce los derechos lesionados de los regidores de Madrid y, de alguna manera, el tratamiento indecoroso de que habian sido objeto y por el cual exigieron no figurase en los libros de la Sala de Alcaldes ${ }^{75}$.

Aunque a simple vista la inspección de abastos de una ciudad puede parecer un hecho de escasa relevancia, lo cierto es, como hemos podido comprobar, que para los representantes del municipio tenía el mayor significado. $Y$ no tanto porque tasando los precios de los artículos contribuyesen a mejorar la calidad de vida de sus gobernados, como por tratarse de una prerrogativa esencial de sus cargos. La creación en 1569 de los fieles ejecutores y la limitación que suponia para el concejo sus amplias atribuciones en la materia, provocó airadas protestas del Ayuntamiento madrileño - lo mismo debía suceder en otras localidades-, con el resultado de que Felipe II pocos años después se avino a consumir estos oficios en beneficio de los concejos. De este modo, una vez más, los regidores controlaban la inspección de abastecimiento de la ciudad, auxiliados por los fieles de vara, oficio codiciado como los que más, a pesar de no estar retribuidos, según se refleja en las disputas que se producen en el momento de la elección de las personas más idóneas para el cargo.

La defensa de sus prerrogativas la encontramos, también, en la pugna que sostienen con los Tenientes de Corregidor por los expedientes incoados contra los infractores de la normativa vigente en las posturas y en la calidad de los géneros comercializados, pero, sobre todo, con los Alcaldes de Casa y Corte, con quienes rivalizan hasta el punto de que la Corona tiene que arbitrar las respectivas funciones de estas instituciones. Con todo, la ambigüedad legislativa de la época, provocará altercados frecuentes y litigios duraderos, con intervención del Consejo de Castilla. Con el tiempo, sin embargo, ambas esferas de poder se complementan y los regidores consiguen conservar sus privilegios, aunque eso si, compartiéndolos con los Alcaldes de Casa y Corte con quienes coinciden en su preocupación por garantizar el perfecto abastecimiento de la ciudad y, con ello, la quietud de sus habitantes, origen a menudo de graves alteraciones del orden público, de resonancias imprevisibles, sobre todo cuando se trata de una ciudad que, como Madrid, puede estallar en

${ }^{75}$ A.V.M. Secretaria. Leg. 3404.38. 
cualquier momento por la actividad política de alborotadores a sueldo de las potencias rivales, interesadas en crear un desorden que les beneficia, como así sucedió en 1699 con el Motín de los Gatos y en 1766 con el Motin de Esquilache. 